\title{
Enhancement of lipopolysaccharide-induced tumor necrosis factor secretion by hyperimmune serum from chronic infected patients
}

\author{
Gitte Kronborg, Anders Fomsgaard, Niels Høiby \\ Department of Clinical Microbiology and The Danish CF Center at Rigshospitalet, \\ Juliane Maries vej 28,2 DK-2100 Copenhagen $\emptyset$, Denmark
}

Received: 21 May 1993

\begin{abstract}
Patients with cystic fibrosis (CF) and chronic Pseudomonas aeruginosa lung infection have a very high load of endotoxins in their lungs. However, sepsis practically never occurs in this group of patients and the presence of tumor necrosis factor (TNF)- $\alpha$ (one of the mediators of septic shock) in serum from chronically infected CF patients is contentious. The purpose of this study was to investigate the effect of hyperimmune serum from patients with CF on lipopolysaccharide (LPS, endotoxin)-induced TNF secretion from human peripheral blood mononuclear cells (PBMC). PBMC were purified from healthy donors and stimulated with a mixture of purified LPS from $P$. aeruginosa and serum from chronically infected CF patients or healthy controls. TNF in the cell supernatants was detected by an enzyme-linked immunosorbent assay method. $\mathrm{CF}$ sera showed a pronounced potentiating effect on TNF secretion from human PBMC induced by LPS from $P$. aeruginosa. In comparison, serum from healthy controls did not have this effect. By contrast, CF serum and serum from healthy controls showed only little potentiating effect when using LPS from Salmonella abortus equi at concentrations above $0.01 \mu \mathrm{g} / \mathrm{ml}$ per $2 \times 10^{6} \mathrm{PBMC}$. This indicates a specific interaction between $P$. aeruginosa LPS and CF serum which enhances TNF secretion. The TNF responses varied depending on the sera used in the preincubation with LPS, and correlated positively to the specific IgG, $\operatorname{IgA}$, and IgM anti-P. aeruginosa LPS titers of the sera. However, since TNF is hardly detectable in sera from these patients another LPS- and/or TNF-inhibitory activity may be present in these sera.
\end{abstract}

\section{Introduction}

Immune complexes (ICs) involving antigens from Pseudomonas aeruginosa are thought to play a central role in the pathogenesis of the chronic inflammatory lung 
disease seen in patients with cystic fibrosis (CF) and chronic P. aeruginosa lung infection $[16,17,19,28,36]$. We have previously identified $P$.aeruginosa lipopolysaccharide (LPS) as an antigenic component in ICs isolated from sputum of chronically infected CF patients $[19,21]$.

Tumor necrosis factor-(TNF)- $\alpha$ is one of the most important inflammatory mediators because of its pivotal position in the cytokine network. Both LPS and ICs are known to induce TNF secretion from monocytes and macrophages [8]. $\mathrm{TNF}$ has been detected in high concentrations in sputum samples from chronically infected CF patients, and the TNF concentration was significantly higher in those samples which also contained ICs involving $P$. aeruginos $a$ LPS as an antigen [21]. No TNF was detectable in serum samples from these patients [21, 22].

LPS is a biologically active molecule and one purpose of this study was to investigate if IC formation acted to neutralize suggested harmful effects of LPS in the chronic CF infection. Inhibition of LPS effects by serum from healthy donors has been demonstrated by several authors [13, 27, 38, 41], using the Limulus amebocyte lysate assay. Under certain conditions interaction of serum with LPS has also been shown to prevent LPS-induced mediator release $[5,9,29,42]$ and this inhibitory effect has been shown to involve the lipoprotein fraction of the serum [9], the alpha globulins [38] and naturally occurring IgG anti-LPS antibodies [13].

CF patients with chronic $P$. aeruginosa lung infecton have a very high load of bacteria and LPS locally in the lungs $[2,19]$ but symptoms of endotoxemia are practically never seen. However, the findings of TNF in serum from these patients are contradictory $[21,22,39]$. It is possible that the immune response of the CF patients in part explains this observation since high levels of anti- $P$. aeruginosa LPS antibodies have been detected systemically and locally in the lungs of CF patients $[11,20]$. However, the effect of these antibodies, in terms of binding of LPS and consequent IC formation, may be an important factor in the continually proceeding destructive inflammatory reactions in the lungs which eventually cause the death of these patients. It is not known whether the formation of LPS-anti-LPS ICs in the lungs and in the circulation reduces or enhances the cytokine-inducing properties of LPS.

The purpose of this study was to investigate the effect of serum from chronically infected CF patients on P. aeruginosa LPS induced TNF secretion from human peripheral blood mononuclear cells (PBMCs), and to compare this with the effect of $P$. aeruginosa LPS alone.

\section{Materials and methods}

\section{Sera}

Sera from eight chronically $P$. aeruginosa-infected CF patients and eight age-matched healthy controls were obtained by venipuncture and collection of blood in endotoxin free vacuocontainers. The P.aeruginosa infection was defined as chronic when $P$. aeruginosa has been cultured continously for 6 months in samples of bronchial secretions, which usually coincides with a significantly increased antibody response against $P$. aeruginosa [31]. All samples were handled under sterile conditions to avoid endotoxin contamination. The sera were heat inactivated at $56^{\circ} \mathrm{C}$ for $30 \mathrm{~min}$ and stored at $-20^{\circ} \mathrm{C}$ until use. IgG, IgA, and IgM anti-P. aeruginosa LPS antibodies in the sera were measured by ELISA as described previously [20]. 


\section{LPS preparations}

Smooth form LPS (S-LPS) from P. aeruginosa and Salmonella abortus equi were both extracted by the hot phenol-water method [43], purified by ultracentrifugation and converted to their triethylamine salt form by electrodialysis as described earlier [10]. Both LPS preparations contained less than $3 \%$ proteins and no detectable nucleic acids [10]. The $P$. aeruginosa $1118 \mathrm{Habs}$ $\mathrm{O}$ group $3(\mathrm{O}: 3)$ was isolated from a patient with $\mathrm{CF}$ and chronic lung infection. The $0: 3$ strain was chosen because it is the most common among CF patients in Denmark [30].

\section{"IC formation"}

To determine the optimum antigen/antiserum ratio for IC formation, using $P$. aeruginosa LPS and CF serum a quantitative precipitation test was carried out as described previously [18]. LPS and sera were serially diluted in endotoxin-free $0.15 \mathrm{M} \mathrm{NaCI}$ in sterile endotoxin free glass tubes, mixed, and incubated at $37^{\circ} \mathrm{C}$ for $1 \mathrm{~h}$ in a shaker. Absorption at $599 \mathrm{~nm}$ was measured, and the optimum concentration of LPS determined by this method was $44 \mu \mathrm{g} / \mathrm{ml}$ in sera diluted to $20 \%$. In control experiments serum and LPS were treated separately using the same methods. To confirm the presence of ICs in the mixture, PEG precipitations were carried out as previously described [18], and the identity of the components involved in the PEG-precipitated samples were confirmed using SDS-PAGE and immunoblotting [21] or a more sensitive dot blot assay [21]. The LPS component was identified using a monoclonal anti-P. aeruginosa $0: 3$ LPS antibody (produced at the State Seruminstitute, Copenhagen, Denmark). The IgG components were identified with monoclonal anti-IgGl, 2, 3, and 4 (Janssen Biochimica, Belgium), and IgA and IgM were demonstrated by monospecific rabbit anti-human IgA and IgM antibodies (Dako, Glostrup, Denmark). The ICs were either used for cell stimulation immediately after formation or stored at $-80^{\circ} \mathrm{C}$ and used within a week after preparation. LPS from $S$. abortus equi and sera from healthy controls (NHS) were used at the same concentrations as $P$. aeruginosa LPS and CF sera.

\section{Cell activation}

PBMC were isolated from heparinized blood of healthy individuals by density gradient centrifugation on Lymphoprep (Nyegaard, Oslo, Norway), washed three times in medium (RPMI 1640 with $25 \mathrm{mM}$ Hepes and L-glutamine from Biological Industries, Kibbutz Beth Haemek, Israel, supplemented with penicillin and streptomycin) and resuspended in medium containing $0.2 \%$ NHS to a cell concentration of $4 \times 10^{6} / \mathrm{ml}$. Cell suspension $(100 \mu \mathrm{l})$ was incubated with $100 \mu \mathrm{l}$ of the sample under investigation in the wells of a 96-well flat-bottom cell culture plate (Nunc, Roskilde, Denmark) for $18 \mathrm{~h}$ at $37^{\circ} \mathrm{C}$. An 18 -h incubation was chosen because of convenience, and because a plateau was seen in the TNF secretion. After incubation the cell supernatants were analyzed for TNF. Each experiment was performed in duplicate, and each set of experiments was performed at least two times using different cell donors. Comparisons between the TNF responses produced by each sample were only made in experiments carried out using the same cell donor on the same day.

\section{TNF assay}

TNF was detected by a double-antibody sandwich ELISA as described previously [12]. Briefly, 96-well microtest plates (maxisorp, Nunc, Roskilde, Denmark) were coated overnight with rabbit anti-TNF in carbonate buffer, $\mathrm{pH}$ 9.8. After washing, samples and a human recombinant ( $\mathrm{r}$ ) TNF standard (Genzyme, corp. Mass. USA) diluted in buffer [PBS, pH 7.4, 0.5\% HSA (w/v) containing $10 \%$ normal rabbit serum $(\mathrm{v} / \mathrm{v})(\mathrm{Dako})$ and $0.05 \%(\mathrm{w} / \mathrm{v})$ Tween 20$]$, were incubated on a shaker for $1 \mathrm{~h}$ at room temperature, followed by biotinylated rabbit anti-TNF, streptavidin- 


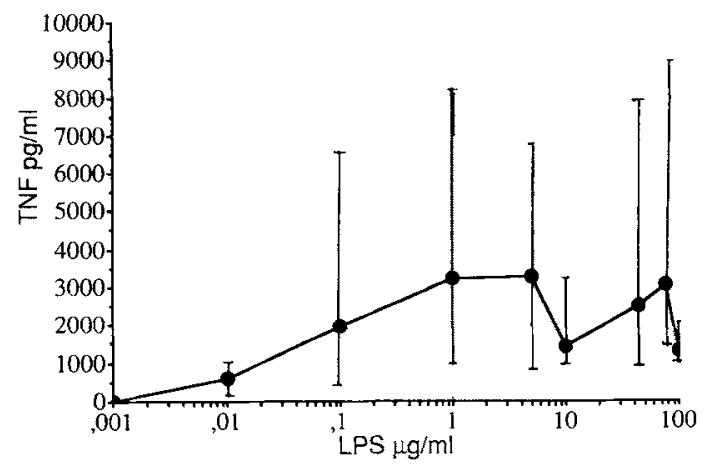

Fig. 1. The mean and range of Pseudomonas aeruginosa lipopolysaccharide (LPS)-induced tumor necrosis factor (TNF) secretion from human mononuclear cells isolated from 11 healthy donors

labelled peroxidase and enzyme substrate [ $12 \mathrm{mg}$ of o-phenylenediamine (Dako) in $18 \mathrm{ml}$ of distilled water plus $7.5 \mu$ hydrogen peroxide $30 \%(\mathrm{v} / \mathrm{v})]$. Washing between the steps was performed in $0.15 \mathrm{~mol} / 1$ sodium chloride containing $0.1 \%$ Tween 20 . The enzyme reaction was stopped with $100 \mu \mathrm{l}$ sulfuric acid $25 \%$ (w/v) per well and the absorbance was measured at $492 \mathrm{~nm}$ with a microtest plate photometer (2550 enzyme immunoassay reader; Bio-Rad Laboratories). The sensitivity was $30 \mathrm{pg} / \mathrm{ml}$ rTNF.

\section{Statistics}

Mann-Whitney U test was used for non-parametric unpaired data, Wilcoxon signed rank test for non-parametric paired data, and Spearman correlation test for correlation analysis of nonparametric data (Macintosh Statview and graphic software).

\section{Results}

\section{LPS-induced TNF response}

S-LPS from $P$. aeruginosa O:3 stimulated PBMC to release TNF. The TNF response was dose dependent, with increasing amounts of TNF released from $2 \times 10^{6} \mathrm{PBMC} / \mathrm{ml}$ when the LPS concentrations were increased from 0.001 to $1.0 \mu \mathrm{g} / \mathrm{ml}$. No further increase was seen above this concentration, and in most cell donors a decreasing TNF response were observed when $1.0 \mu \mathrm{g} / \mathrm{ml}$ of $P$. aeruginosa LPS was exceeded (Fig. 1). The amount of TNF released at a given LPS concentration varied within a wide range dependent on the cell donor (Fig. 1).

Fig. 2. a Induction of TNF by $P$. aenuginosa LPS and LPS preincubated with $20 \%$ serum from one representative cystic fibrosis (CF) patient, chronically infected with $P$. aeruginosa. b Induction of TNF by $44 \mu \mathrm{g} / \mathrm{ml} P$. aeruginosa LPS with varying concentrations of serum from one representative CF patient, chronically infected with $P$. aeruginosa, and from one healthy control (NHS), and the varying concentrations of the two serum samples without any addition and preincubation with LPS. c TNF response induced by $44 \mu \mathrm{g} / \mathrm{ml}$ LPS from $P$. aeruginosa $(P a)$ and $S$. abortus equi (S.ab.eq.), the same amount of LPS preincubated with $20 \%$ serum from CF patients or $20 \%$ serum from healthy controls, and $20 \%$ serum without LPS. The TNF concentrations are median values from one experiment using sera from eight different CF patients and eight different healthy controls for individual incubations with the respective LPSs followed by cell stimulation. The ranges for the four serum + LPS groups were as follows: Pa LPS + NHS 940-3100, Pa LPS + CF 2400-10000, S.a.eq. LPS + NHS 3200-9000, S.ab. eq. LPS + CF 3500-13600. Standard error of deviations are indicated 

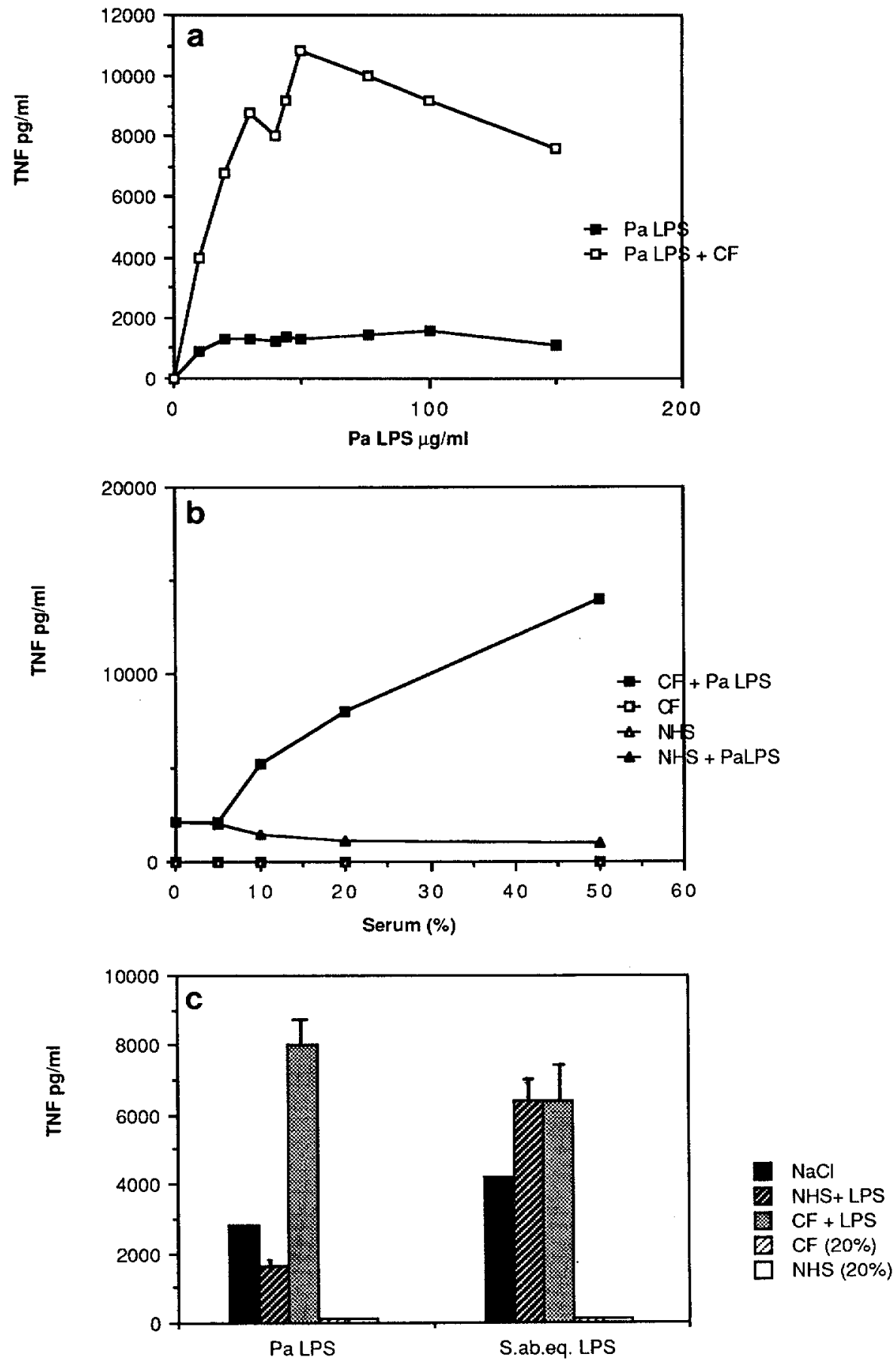


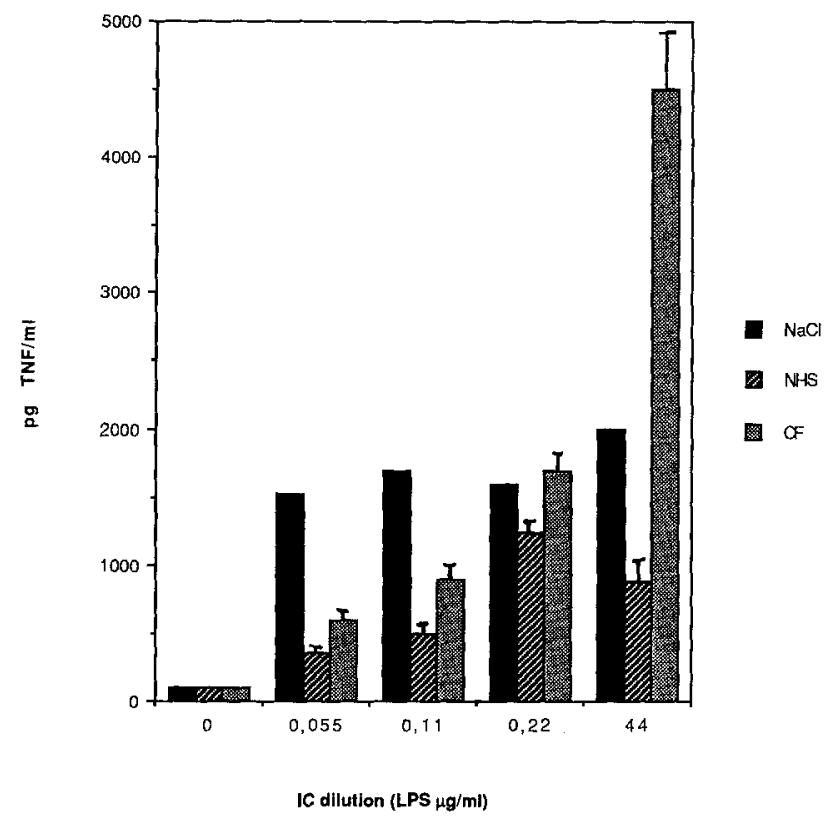

Fig. 3. TNF response induced by $44 \mu \mathrm{g} / \mathrm{ml} P$. aeruginosa LPS preincubated with $20 \%$ serum from either CF patients or healthy controls. The immune complex (IC) samples were diluted $\times 200$, $\times 400$, and $\times 800$ and are expressed as the equivalent LPS concentration. The serum concentrations were in the dilutions $0.10 \%, 0.05 \%$, and $0.025 \%$, respectively. The TNF concentrations are median values from one experiment using sera from eight different $C F$ patients and eight different healthy controls for individual incubations with the respective LPSs followed by cell stimulation. The ranges of the median values were as folows: 0.055 NHS 240-440, CF 440-920, 0.11 NHS 320800 , CF 560-1400, 0.22 NHS 440-1520, CF 1120-2000, 44 NHS 580-1180, CF 1400-5200. Standard error of deviations are indicated

\section{"IC"-induced TNF response}

For optimal IC formation we chose $44 \mu \mathrm{g} / \mathrm{ml}$ LPS and $20 \%$ serum since these concentrations were the point of equivalence using sera from CF patients and P. aeruginosa LPS in the turbidimetric method. When the LPS preparations were incubated with human serum and the mixture then used for cell stimulation the TNF response changed depending on the source of the LPS ( $P$. aeruginosa versus $S$. abortus equi), the LPS concentration, the serum concentration, and whether the sera were from healthy controls or chronically infected patients with CF (Fig. 2). The eight CF sera and eight NHS used in the experiments did not induce any TNF secretion by themselves in the relevant concentrations (Fig. 2b). Using $44 \mu \mathrm{g} / \mathrm{ml}$ of LPS from P. aeruginosa together with CF sera potentiated the TNF response as compared to the same concentration of LPS without any preincubation with serum (Fig. 2a, c, $P=0.007$, using Wilcoxon signed rank test). Increasing the concentration of CF serum while keeping the $P$. aeruginosa LPS concentration fixed induced increasing amounts of TNF (Fig. 2b). This was in contrast to the TNF response seen when PBMCs were stimulated with $P$. aeruginosa LPS and NHS together (Fig. 2b, c, $P<0.0011$ comparing the two groups of sera, using Mann-Whitney U 

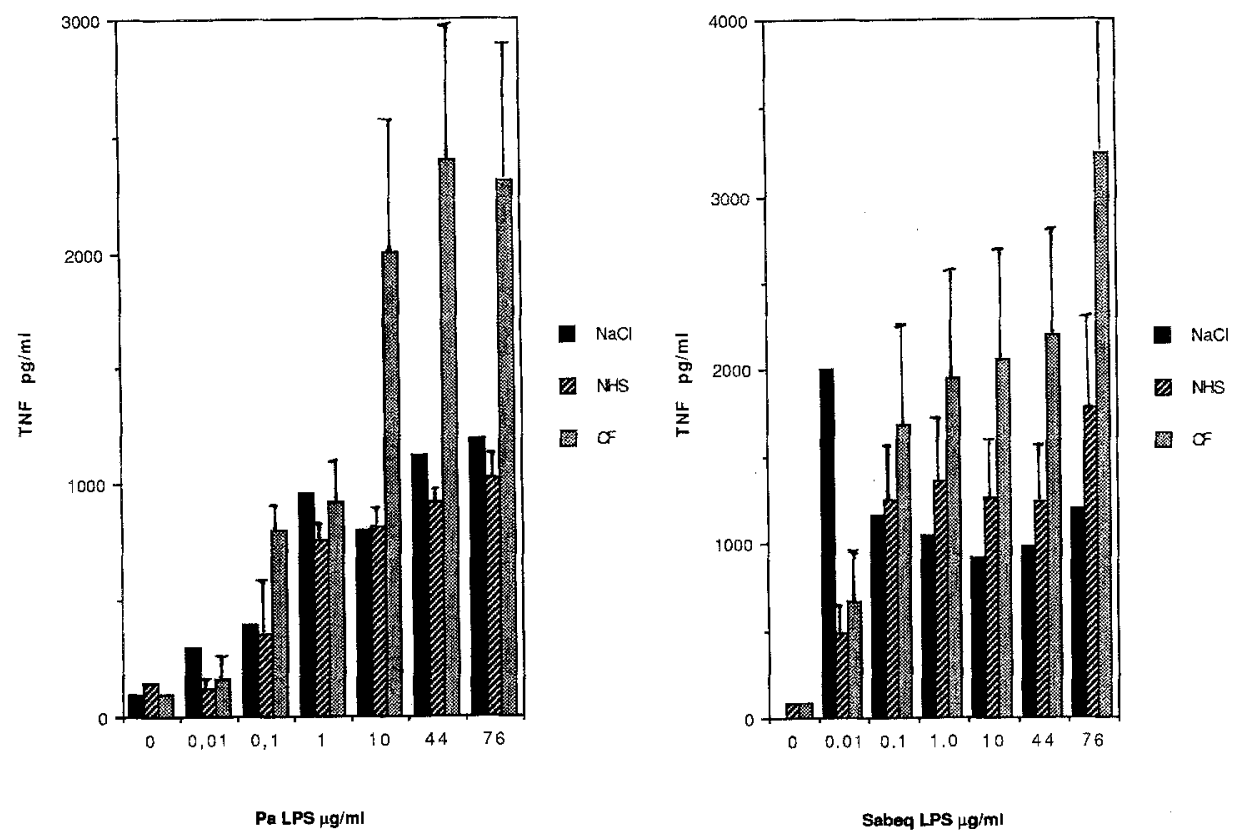

Fig. 4. TNF response induced by varying amounts of LPS from $P$. aeruginosa $(P a)$ and $S$. abortus equi (Sabeq), the same amounts of LPS preincubated with $20 \%$ serum from CF patients or healthy controls (NHS), and $20 \%$ serum without LPS (= LPS concentration 0$)$. The TNF concentrations are median values from one experiment using sera from eight different $C F$ patients and eight different healthy controls for individual incubations with the respective LPSs followed by cell stimulation. The ranges of the median values were as follows in the order of increasing LPS concentrations: Pa/NHS (0-200), (90-520), (440-2200), (1600-2600), (1680-3800), 1760-3900), (2000-3400). Pa/CF (480-3600), (1000-4800), (900-6000), (2100-10800), (2400-10000), (2200$8800)$. Sabeq/NHS $(0-240),(192-920),(800-2500),(1000-2800),(940-2500),(1000-2900),(1200-$ $4300)$. Sabeq/CF $(90-1680),(200-3400),(480-4000),(820-4400),(800-4600),(900-5800)$. Standard error of deviations are indicated

test). The TNF response decreased with dilution of the ICs which was not due to a decrease in just P. aeruginosa LPS (Fig. 3), since the TNF response was not decreasing when diluting the P. aeruginosa LPS from $0.22 \mu \mathrm{g} / \mathrm{ml}$ to $0.11 \mu \mathrm{g} / \mathrm{ml}$ and $0.055 \mu \mathrm{g} / \mathrm{ml}$ in contrast to the decreasing TNF response when the CF serum/LPS mixture was diluted (Fig. 3). Applying LPS from S. abortus equi to the cells together with serum having low anti-S. abortus equi LPS titers induced a higher TNF response than LPS alone when more than $0.01 \mu \mathrm{g} / \mathrm{ml}$ LPS was used (Fig. 4), indicating a general potentiating effect of serum on LPS-induced TNF secretion, using high amounts of LPS. Increasing amounts of CF sera or NHS together with $44 \mu \mathrm{g} / \mathrm{ml}$ S. abortus equi LPS did not increase the TNF response above the level seen using $5 \%$ serum (not shown), probably because of lack of IC formation. In some of the experiments a difference in the TNF induction was seen between using either NHS or CF sera together with S. abortus equi LPS, but this difference did never reach significant levels (Figs. 2c, 4).

The TNF response induced by $P$. aeruginosa LPS mixed with the different sera showed an individual variation which depended on the serum and correlated 
Table 1. Anti-LPS ELISA titers

\begin{tabular}{|c|c|c|c|c|}
\hline & \multicolumn{3}{|c|}{ Anti-P. aeruginosa LPS } & \multirow{2}{*}{$\frac{\text { Anti-S. abortus equi LPS }}{\text { IgG }}$} \\
\hline & $\operatorname{IgG}$ & $\operatorname{Ig} \mathrm{A}$ & $\operatorname{IgM}$ & \\
\hline \multicolumn{5}{|c|}{ Healthy controls $(n=8)$} \\
\hline $\begin{array}{l}\text { median } \\
\text { (range) }\end{array}$ & $\begin{array}{l}80 \\
(53-127)\end{array}$ & $\begin{array}{l}32 \\
(0-69)\end{array}$ & $\begin{array}{l}352 \\
(173-647)\end{array}$ & $\begin{array}{l}1.7 \\
(0-4.5)\end{array}$ \\
\hline \multicolumn{5}{|c|}{ CF patients $(n=8)$} \\
\hline median & $\begin{array}{l}3200 \\
(1067-13332)\end{array}$ & $\begin{array}{l}1018 \\
(333-1666)\end{array}$ & $\begin{array}{l}733 \\
(186-1173)\end{array}$ & $\begin{array}{l}0.76 \\
(0.22-5.4)\end{array}$ \\
\hline
\end{tabular}

The differences in anti-Pseudomonas aeruginosa lipopolysaccharide (LPS) titers between the two groups were significant for all three classes of immunoglobulins, $(P=0.0005$ for $\operatorname{IgG}$ and $\operatorname{lgA}$, $P=0.05$ for IgM, Mann-Whitney U test). There was no significant difference in IgG antiSalmonella abortus equi LPS between the two groups

positively to the specific anti- $P$. aeruginosa LPS ELISA titers of the respective sera. The correlations were shown with IgG, IgA and IgM and were most pronounced with IgA anti-P. aeruginosa LPS (coefficients of correlation were: $0.56,0.80$, and 0.54 , respectively, and the corresponding $P$ values: $0.03,0.002$, and 0.04 , using Spearmans correlation test). The IgG, IgA, and IgM anti-P. aeruginosa LPS titers, IgG anti-S. abortus equi LPS are given in Table 1.

In control experiments to investigate if the sera used together with LPS for cell stimulation had any effect on the TNF concentration after secretion from the PBMCs, supernatants from cell stimulation experiments were re-incubated with homologous sera, in the same concentration as in the primary experiment $(20 \%)$, and re-incubated for another $18 \mathrm{~h}$ at $37^{\circ} \mathrm{C}$. TNF recovery after re-incubation measured by ELISA varied from $81 \%$ to $114 \%$ demonstrating a lack of TNF inhibitory components in the sera.

\section{Discussion}

Although the levels of anti-LPS antibodies are increased considerably during chronic $P$. aeruginosa infection the bacteria are not eradicated so that LPS antigen remains in the lung. IC formation by LPS and anti-LPS anibodies could modify the biological effects of LPS alone. LPS is a potent inducer of TNF and in this study we have investigated the effect of LPS together with hyperimmune anti-LPS sera on TNF induction from PBMCs. Our results showed a potentiating effect of hyperimmune serum from chronically infected CF patients on high concentrations ( $>100-1000 \mathrm{ng} / \mathrm{ml}$ ) of purified P. aeruginosa LPS induced TNF secretion from PBMCs. The results indicate that this effect could be due to IC formation between $P$. aeruginosa LPS and specific antibodies present in these sera. The IC-induced TNF response was significantly higher than the TNF response elicited by the same amount of $P$. aeruginosa LPS alone. The IC-induced cytokine release from PBMCs seen in these experiments is in agreement with earlier studies showing an induction of either interleukin-1 (IL-1) or TNF when PBMCs were stimulated with ICs $[1,6$, 
8, 33]. Arend et al. [1] showed that the IL-1 inducing capacity of ICs was dependent on the presence of complement. However, Remvig et al. [33] showed an IC-induced IL-1 production in PBMCs also without any complement in the system. In our experiments we used heat-inactivated sera and, thus, complement was not needed for the TNF induction by ICs. The effect of complement was not studied, but from recently published experiments by Heumann et al. [15] it is likely that addition of complement would further enhance the TNF secretion. Debets et al. [8] have shown that cross-linking of Fc receptors on human PBMCs by anti-human kappachain antibodies induced a rapid secretion of TNF, and that a TNF response was also induced by a standard IC preparation consisting of tetanus toxoid and human IgG anti-tetanus toxoid [8].

The considerable variation in LPS-induced TNF response among PBMC donors has been described before [3] and may be related to genetic HLA-DR2 variations [3]. However, the phenomenon of IC-induced TNF secretion was seen with all cell donors used. To minimize the variation due to this donor variation we, therefore, only compared results from experiments made with the same cell donor the same day.

LPS from $S$. abortus equi was chosen as a control since there was no difference in IgG anti-S. abortus equi LPS titers between the CF patients and the healthy controls. The inactivation of small amounts of $S$. abortus equi LPS $(0.01 \mu \mathrm{g} / \mathrm{ml})$ by serum from healthy controls described in this study supports previous studies, in which the LPS-induced IL-1 or TNF response was inhibited by normal human serum or purified serum proteins as lipoproteins, IgG or alpha globulins $[9,13,38]$. Interestingly, NHS seemed to have a slightly neutralizing effect on even high concentrations of $P$. aeruginosa LPS compared to that of $S$. abortus equi LPS [0.01$76 \mu \mathrm{g} / \mathrm{ml}$ of $P$. aeruginosa LPS compared with $0.01 \mu \mathrm{g} / \mathrm{ml}$ S. abortus equi LPS (Fig. 4)]. This is in agreement with the lower potency of $P$. aeruginosa LPS for TNF induction [13], which could be due to the slightly different structure of this LPS molecule compared to the S. abortus equi LPS [24]. P. aeruginosa LPS differs from enterobacterial LPS by having a large number of phosphate residues, by the presence of L-alanine in the core, by the occurrence of unusual sugars and amino compounds in the $O$ chain $[32,35]$, and by having fewer and shorter fatty acid residues in the lipid A part arranged asymetric on the glucosamine backbone $[4,10$, 25].

We have previously determined $P$. aeruginosa LPS, IgG and IgA to be the most characteristic components of ICs isolated from sputum in patients with CF and chronic pulmonary infection $[19,21]$. Our results suggest indirectly that ICs formed from LPS and CF anti-LPS antibodies are in fact more potent activators in terms of inducing a TNF response from PBMCs than $P$. aeruginosa LPS alone. The lack of TNF inhibiting effect of the specific anti-LPS antibodies in CF serum was further supported when we did not find any protective effect to lethality using the CF sera with $P$. aeruginosa LPS in a D-galactosamine-sentisized mouse model (unpublished data). Using serum as the antibody source in the IC formation could lead to binding of LPS by serum proteins other than immunoglobulins. Thus, lipoproteins and LPS-binding protein are serum proteins which are known to bind specifically to LPS $[40,44]$. LPS bound to LPS-binding protein has been shown to activate PBMCs via the CD14 receptor for TNF production, and LPS-binding protein has been shown to be necessary for LPS-induced TNF production, but only when the LPS concentrations were below $0.01 \mu \mathrm{g} / \mathrm{ml}(37,45]$. With higher concentrations of LPS the cell stimulation might occur via putative LPS receptors 
$[7,14,34]$. Bactericidal/permeability-increasing protein is another specific LPSbinding protein, but it is mainly contained in neutrophil granules [26], and it has a neutralizing effect on the biological activity of LPS rather than potentiating. Our results indicate a potentiating effect of CF sera on TNF secretion from PBMCs induced by $P$. aeruginosa LPS at concentrations above $0.01 \mu \mathrm{g} / \mathrm{ml}$, this could be due to IC formation between $P$. aeruginosa LPS and specific antibodies in the sera, followed by binding to Fc receptors on the cells and the induction of TNF secretion. Since no significant difference in TNF induction was seen between sera from CF patients and healthy controls together with $S$. abortus equi LPS a specific interaction between $P$. aeruginosa LPS and CF serum is indicated.

We have previously used the same IC preparations made from CF sera and $P$. aeruginosa LPS for stimulation of neutrophil granulocytes and showed an oxidative burst response induced by the ICs compared to no response when the cells were stimulated with P. aeruginosa LPS or CF serum alone [23]. It is interesting that the interaction of anti-LPS antibodies apparently augments the potential of these endotoxins to induce TNF in vitro. However, other endotoxic effects may be inhibited in the circulation and the molecules are finally opsonized by antibodies and complement and cleared by the reticoluendothelial system in vivo, depending on antibody specificity, isotype, and host species. This is in agreement with our previous results from sputum and serum of CF patients with chronic $P$. aeruginosa infection, where we showed a high local TNF concentration in the patients with LPS ICs in the lungs, whereas no systemic TNF was detected in these patients [21].

In summary, our results are in agreement with the hypothesis, drawn from these experiments, that ICs stimulates TNF secretion in PBMCs via Fc receptors (which do not respond to LPS alone) independent on complement, and, thereby, may contribute to the lung tissue damage seen in chronic $P$. aeruginosa-infected patients with CF. However, the results do not give any explanation of the non-detectable levels of TNF in the serum samples from our group of chronically infected CF patients, and the extrapolation from our in vitro experiments to the in vivo situation of the CF lung disease can only be related to the possible mechanism of IC-induced inflammation.

Acknowledgements. We are grateful to G. H. Shand for critical review of the manuscript and to Lisbeth Heiden for skillful technical assistance.

\section{References}

1. Arend WP, Joslin FG, Massoni RJ (1985) Effects of immune complexes on production by human monocytes of interleukin 1 or an interleukin 1 inhibitor. J Immunol 134:3868-3875

2. Baltimore RS, Christie CDC, Smith GJW (1989) Immunohistopathologic localization of Pseudomonas aeruginosa in lungs from patients with cystic fibosis. Am Rev Respir Dis $140: 1650-1661$

3. Bendtzen K, Morling N, Fomsgaard A, Svenson M, Jacobsen B, Ødum N, Svejgaard A (1988) Association between HLA-DR2 and production of tumour necrosis factor $\alpha$ and interleukin 1 by mononuclear cells activated by lipopolysaccharide. Scand J Immunol 28:599-600

4. Bhat R, Marx A, Galanos C, Conrad RS (1990) Structural studies of lipid A from Pseudomonas aeruginosa PA01: occurrence of 4-amino-4-deoxyarabinose. J Bacteriol 172:6631-6636

5. Cavaillon J-M, Fitting C, Haeffner-Cavaillon N, Kirsch SJ, Warren HS (1990) Cytokine response by monocytes and macrophages to free and lipoprotein-bound lipopolysaccharide. Infect Immun 58:2375-2382 
6. Chantry D, Winearls CG, Maini RN, Feldmann M (1989) Mechanism of immune complexmediated damage: induction of interleukin-1 by immune complexes and synergy with interferon- $\gamma$ and tumor necrosis factor- $\alpha$. Eur J Immunol 19:189-192

7. Couturier C, Haeffner-Cavaillon N, Caroff M, Kazatchinke MD (1991) Binding sites for endotoxins (lipopolysaccharides) on human monocytes. J Immunol 147:1899-1904

8. Debets JMH, Van der Linden CJ, Dieteren IEM, Leeuwenberg JFM, Buurman WA (1988) Fc-receptor cross-linking induces rapid secretion of tumor necrosis factor (cachectin) by human peripheral blood monocytes. J Immunol 141:1197-1201

9. Flegel WA, Wölpl A, Männel DN, Northoff H (1989) Inhibition of endotoxin-induced activation of human monocytes by human lipoproteins. Infect Immun 57:2237-2245

10. Fomsgaard A, Conrad RS, Galanos C, Shand GH, Høiby N (1988) Comparative immunochemistry of lipopolysaccharides from typable and polyagglutinable Pseudomonas aeruginosa strains isolated from patients with cystic fibrosis. J Clin Microbiol 26:821-826

11. Fomsgaard A, Høiby N, Shand GH, Conrad RS, Galanos C (1988) Longitudinal study of antibody response to lipopolysaccharides during chronic Pseudomonas aeruginosa lung infection in cystic fibrosis. Infect Immun 56:2270-2278

12. Fomsgaard A, Worsaae H, Bendtzen K (1988) Detection of tumour necrosis factor from lipopolysaccharide-stimulated human mononuclear cells by enzyme-linked immunosorbent assay and cytotoxicity bioassay. Scand J Immunol 27:143-147

13. Fomsgaard A, Zhang G-H, Shand GH, Bendtzen K, Baek L (1989) Immunochemical and biological reactivity of human anti-lipopolysaccharide IgG obtained by screening of blood donors. Scand J Immunol 29:309-316

14. Halling JL, Hamill DR, Lei M-G, Morrison DC (1992) Identification and characterization of lipopolysaccharide-binding proteins on human peripheral blood cell populations. Infect Immun 60:845-852

15. Heumann D, Gallay P, Barras C, Zaech P, Ulevitch RJ, Tobias PS, Glauser M-P, Baumgartner JD (1992) Control of lipopolysaccharide (LPS) binding and LPS-induced tumor necrosis factor secretion in human peripheral blood monocytes. J Immunol 148:35053512

16. Hornick DB, Fick RB Jr (1990) The immunoglobulin G subclass composition of immune complexes in cystic fibrosis. J Clin Invest 86:1285-1292

17. Høiby N, Döring G, Schiøtz PO (1986) The role of immune complexes in the pathogenesis of bacterial infections. Annu Rev Microbiol 40:29-53

18. Kronborg G, Fomsgaard A, Shand GH, Høiby N (1989) Determination of the components of immune complexes made in vitro with antigens derived from Pseudomonas aeruginosa. J Immunol Methods 122:51-57

19. Kronborg G, Shand GH, Fomsgaard A, Høiby N (1992) Lipopolysaccharide is present in immune complexes isolated from sputum in patients with cystic fibrosis and chronic Pseudomonas aeruginosa lung infection. APMIS 100:175-180

20. Kronborg G, Fomsgaard A, Galanos C, Freuenberg MA, Høby N (1992) Antibody responses to lipid $\mathrm{A}$, core, and $\mathrm{O}$ sugars of the Pseudomonas aeruginosa lipopolysaccharide in chronically infected cystic fibrosis patients. J Clin Microbiol 30:1848-1855

21. Kronborg G, Fomsgaard A, Shand GH, Lanng S, Hansen MB, Pressler T, Høiby N (1992) TNF- $\alpha$ and immune complexes in sputum and serum from patients with cystic fibrosis and chronic Pseudomonas aeruginosa lung infection. Immunol Infect Dis 2:171-177

22. Kronborg G, Hansen MB, Svenson M, Fomsgaard A, Høiby N, Bendtzen K (1993) Cytokines in sputum and serum from patients with cystic fibrosis and chronic Pseudomonas aeruginosa lung infection as markers of destructive inflammation in the lungs. Pediatr Pulmonol 15:292297

23. (Reference deleted)

24. Kropinski AM, Jewell B, Kuzio J, Milazzo F, Berry D (1985) Structure and function of Pseudomonas aeruginosa lipopolysaccharide. Antibiot Chemother 36:58-73

25. Kulshin VA, Zähringer U, Lindner B, Jäger K-E, Dmitriev BA, Rietschel ET (1991) Structural characterization of the lipid A component of Pseudomonas aeruginosa wild-type and rough mutant lipopolysaccharides. Eur J Biochem 198:697-704

26. Marra MN, Wilde CD, Griffith JE, Snable JL, Scott RW (1989) Bactericidal/permeabilityincreasing protein has endotoxin neutralizing activity. J Immunol 144:662-666 
27. Mathison J, Tobias P, Wolfson E, Ulevitch R (1991) Regulatory mechanisms of host responsiveness to endotoxin (lipopolysaccharide). Pathobiology 59:185-188

28. Moss RB, Hsu Y-P, Lewiston NJ, Curd JG, Milgrom H, Hart S, Dyer B, Larrick JW (1986) Association of systemic immune complexes, complement activation, and antibodies to Pseudomonas aeruginosa lipopolysaccharide and endotoxin A with mortality in cystic fibrosis. Am Rev Respir Dis 133:648-652

29. Northoff H, Glück D, Wölpl A, Kubanek B, Galanos C (1987) Lipopolysaccharide-induced elaboration of interleukin 1 by human monocytes: use for detection of lipopolysaccharide in serum and the influence of serum-lipopolysaccharide interactions. Rev Infect Dis 9:S599_ S601

30. Ojeniyi B, Høiby N, Rosdah1 VT (1991) Prevalence and persistence of polyagglutinable Pseudomonas aeruginosa in isolates from cystic fibrosis patients. APMIS 99:187-195

31. Pedersen SS (1992) Lung infection with alginate-producing, mucoid pseudomonas aeruginosa in cystic fibrosis. APMIS 100 [Suppl 28]: 1-79

32. Pier GP, Markham RB, Eardly D (1981) Correlation of the biologic responses of C3H/HEJ mice to endotoxin with the chemical and structural properties of the lipopolysaccharide from Pseudomonas aeruginosa and Escherichia coli. J Immunol 127:184-191

33. Remvig L, Thomsen BS, Baek L, Svenson M, Bendtzen K (1990) Interleukin 1, but not interleukin 1 inhibitor, is released from human monocytes by immune complexes. Scand $\mathrm{J}$ Immunol 32:255-261

34. Roeder DJ, Lei M-G, Morrison DC (1989) Endotoxic-lipopolysaccharide-specific binding proteins on lymphoid cells of various animal species: association with endotoxin susceptibility. Infect Immun 57:1054-1058

35. Rowe PSN, Meadow PM (1983) Structure of the core oligosaccharide from the lipopolysaccharide of Pseudomonas aeruginosa PACIR and its defective mutants. Eur J Biochem $132: 329-337$

36. Schiøtz PO (1981) Local humoral immunity and immune reactions in the lungs of patients with cystic fibrosis. Acta Pathol Microbiol Scand [C] [Suppl] 276:1-25

37. Schumann RR, Leong SR, Flaggs GW, Gray PW, Wright SD, Mathison JC, Tobias PS, Ulevitch RJ (1990) Structure and function of lipopolysaccharide binding protein. Science 249: 1429-1431

38. Scuderi P, Dorr RT, Liddil JD, Finley PR, Meltzer P, Raitano AB, Rybski J (1989) Alphaglobulins suppress human leukocyte tumor necrosis factor secretion. Eur J Immunol 19:939_ 942

39. Suter S, Schaad UB, Roux-Lombard P, Girardin E, Grau G, Dayer J-M (1989) Relation between tumour necrosis factor $\alpha$ and granulocyte elastase- $\alpha 1$-proteinase inhibitor complexes in the plasma of patients with cystic fibrosis. Am Rev Respir Dis 140:1640-1644

40. Ulevitch RJ, Johnston AR, Weinstein DB (1979) New function for high density lipoproteins. Their participation in intravascular reactions of bacterial lipopolysaccharides. J Clin Invest $64: 1516-1524$

41. von Eschen KB, Rudbach JA (1974) Inactivation of endotoxin by serum: a phylogenetic study. J Infect Dis 129:21-27

42. Weinstock C, Ullrich H, Hohe R, Berg A, Baumstark MW, Frey I, Northoff H, Flegel WA (1992) Low density lipoproteins inhibit endotoxin activation of monocytes. Arteriosclerosis Thromb 12:341-347

43. Westphal O, Jann K (1965) Bacterial lipopolysaccharides: extraction with phenol-water and further applications of the procedure. Methods Carbohydr Chem 5:83-91

44. Wright SD, Tobias PS, Ulevitch RJ, Ramos RA (1989) Lipopolysaccharide (LPS) binding protein opsonizes LPS-bearing particles for recognition by a novel receptor on macrophages. J Exp Med 170:1231-1241

45. Wright SD, Ramos RA, Tobias PS, Ulevitch RJ, Mathison JC (1990) CD14, a receptor for complexes of lipopolysaccharide (LPS) and LPS binding protein. Science 249:1431-1433 